\title{
Novo Marco Regulatório para a realização de parcerias entre Estado e Organização da Sociedade Civil (OSC). Inovação ou peso do passado?
}

\author{
New Regulatory Framework for the establishment of partnerships between the state and the CSOs- Civil Society \\ Organizations: innovation or a burden from the past?
}

\section{Nuevo Marco Regulatorio para el establecimiento de alianzas entre el Estado y las Organizaciones de la Sociedad Civil OSCs: ¿la innovación o el peso del pasado?}

Resumo: As parcerias entre Estado e Organização da Sociedade Civil (OSC) são um fenômeno observado em vários países. No Brasil, esse evento também tem tido uma relevância crescente para a disponibilização de serviços públicos. A regulação desses relacionamentos traz em si uma visão particular do Estado com relação à sociedade civil, tendo impactos na elaboração e execução de políticas públicas. Este trabalho discute as limitações e os avanços desse processo, com destaque de como foi a mobilização para se chegar ao novo marco regulatório e a realização da sistematização dos principais pontos de mudança. Argumenta-se que um novo marco jurídico não é suficiente para, sozinho, modificar a trajetória de uma política pública. 0 que se observa é uma bagagem cultural e um legado institucional e normativo que pendem excessivamente para o controle e que têm se exacerbado nos últimos anos por todas as esferas da Administração Pública.

Apesar da articulação das OSC em torno da agenda do Marco Regulatório das Organizações da Sociedade Civil (MROSC) e do retorno positivo a partir da aprovação da Lei 13.204/15, muitos desafios ainda se impõe para a continuidade desse processo, o que via permitir que o marco jurídico se torne uma inovação no âmbito da gestão pública.

Palavras-Chave: Organizações da Sociedade Civil; Estado; Parcerias; Regulação.

Patricia Mendonça - pmendonca@usp.br

Professora da Universidade de São Paulo, Escola de Artes Ciências e Humanidades, São Paulo, SP, Brasil.

Domenica Silva Falcão - domenica.falcao@hotmail.com

Aluna de graduação da Universidade de São Paulo, Escola de Artes, Ciências e Humanidades, São Paulo, SP, Brasil.

Artigo submetido no dia 22-09-2015 e aprovado em 28-02-2016.

DOI: http://dx.doi.org/10.12660/cgpc.v21n68.56484 


\begin{abstract}
Partnerships between CSOs and the state are a phenomenon observed in other countries, and in Brazil they have also become increasingly relevant for the provision of public services. Regulation of these relationships brings about a particular view by the state of civil society, with impacts on the design and implementation of public policies. This paper discusses the limitations and advances of this process, highlights how mobilization occurred to get to the new regulatory framework of partnerships, and systematizes the main points of change in it. It is argued that a new legal framework alone is not enough to change the course of public policy, or the absence of it. What is observed is a cultural background and an institutional and normative legacy that lean excessively towards control and that have been exacerbated in recent years by all levels of public administration.

Despite the articulation of CSOs around the MROSC agenda, and a positive result being reached with enactment of Law 13,204/15, many challenges are still being imposed for the continuity of this process, which can really enable the new legal framework to produce innovation in public management.
\end{abstract}

Keywords: Civil Society Organizations; State; partnerships; regulation

\title{
Resumen
}

Las alianzas entre las OSC y el Estado es un fenómeno que se observa en otros países, y Brasil también ha tenido una relevancia cada vez mayor a la prestación de servicios públicos. La regulación de estas relaciones trae consigo una visión particular desde el estado sobre la sociedad clvil, con impactos en el diseño e implementación de políticas públicas. Este documento analiza las limitaciones y avances de este proceso, destacando cómo fue el proceso de movilización para llegar al nuevo marco regulatorio, y la realización de una sistematización de los principales puntos de cambio. Se argumenta que un nuevo marco legal por sí solo no es suficiente para cambiar la trayectoria de la política pública, o falta de ella. Lo que se observa es un bagaje cultural y un legado institucional y normativo excesivamente pendiente de control y que se han agravado en los últimos años por todos los niveles de la administración pública.

A pesar de la articulación de las OSC en todo el MROSC el orden del día, y un retorno positivo de la promulgación de la Ley 13.204, muchos retos que aún imponen la continuidad de este proceso para que, de hecho, el nuevo marco legal se convierta en una innovación en el ámbito de administración pública.

Palabras clave: Organizaciones de la Sociedad Civil; Estado; Alianzas; regulación

\section{Introdução}

papel e a relevância das Organizações da Sociedade Civil (OSC) no Brasil são amplamente discutidos na esfera política, social e jurídica. Podemos citar alguns aspectos inseridos nessa discussão: definição das OSCs, seu regulamento jurídico, certificações, acesso a recursos públicos, celebração de parcerias com outros setores, formas de participação, organização institucional, formas de atuação e promoção da democracia e de direitos (Peci et al., 2011; Campos, 2008; Alves \& Koga, 2006; Pannunzio, 2014).

As parcerias são um fenômeno observado em vários países. No Brasil, esse evento também tem tido uma relevância crescente para a disponibilização de serviços públicos. Há uma grande diversidade de OSCs, assim como de formatos de parcerias em diferentes contextos (Brinkerhoff \& Brinkerhoff, 2002).

De acordo com as Fundações e Associações Sem Fins Lucrativos - Fasfil - (IBGE, 2012), há no Brasil 290.692 mil OSCs. O Instituto de Pesquisa Econômica Aplicada (Ipea) (ver capítulo de Lopes et al., 2014) identifica que aproximadamente $45 \%$ das OSCs do país mantêm algum tipo de relacionamento direto ou indireto com o governo federal e cerca de $5 \%$ das OSCs brasileiras envolvem-se com algum tipo de transferência de recursos (FGV Projetos, 2014). 
A regulação desses relacionamentos traz em si uma visão particular do Estado com relação à sociedade civil, tendo impactos na elaboração e execução de políticas públicas. Até 2014, não havia um marco regulatório unificado em nível nacional sobre as parcerias. O resultado disso foi a consolidação de um ambiente de insegurança jurídica que trouxe consequências negativas tanto para - poder público, quanto para as entidades (Junqueira \& Figueiredo, 2012; Mendonça \& Segatto, 2012).

Em 2011, foi criado um grupo de discussão sobre o marco regulatório das OSCs, envolvendo diversas entidades e redes dessas organizações, que se dispuseram em torno da Plataforma Marco Regulatório das OSCs (Plataforma OSCs, 2011). O resultado dessa mobilização envolve muitas idas e vindas acerca de delicados pontos que vão culminar na aprovação da Lei 13.019, de maio de 2014, e da Lei 13.240, de dezembro de 2015, modificando a norma anterior, então denominado pelos practioners de novo MROSC (Marco Regulatório das Organizações da Sociedade Civil).

Este estudo discute as limitações e os avanços desse processo, com destaque de como foi a mobilização para se chegar ao novo marco regulatório e a sistematização dos principais pontos de mudança. Para tanto, as autoras realizaram ampla revisão bibliográfica e análise de documentos jurídicos, bem como o acompanhamento, entre $2012 \mathrm{e}$ 2015, de diversos eventos organizados pelo poder público, pelas OSCs e universidades, que puseram em discussão as propostas de mudança. Nesses eventos, que contaram com os principais especialistas da área, bem como atores chave no processo de mobiliza- ção, também foi possível depreender como ocorreram as mobilização para a aprovação das Leis envolvidas no novo marco.

Argumenta-se aqui que um novo marco jurídico não é suficiente para modificar a trajetória de uma política pública. $O$ que se observa é uma bagagem cultural e um legado institucional e normativo que pendem excessivamente para o controle e que têm se exacerbado nos últimos anos por todas as esferas da Administração Pública.

Apesar da articulação das OSCs em torno da agenda do MROSC e do retorno positivo a partir da aprovação da Lei 13.204, muitos desafios ainda se impõe na continuidade desse processo para que de fato o novo marco jurídico se torne uma inovação no âmbito da gestão pública.

\section{A regulação das relações entre Estado e OSC e o peso do passado}

A regulação se constitui numa força institucional que delimita os comportamentos dos atores permitindo, prescrevendo ou proibindo categorias de ações específicas (Ostrom, 1990). O Estado tem poder de interferir no funcionamento das OSCs, por meio da criação de barreiras na entrada e limitações para a atividade política e a aquisição de recursos econômicos dessas organizações, criando, por exemplo, medidas que aumentem seus custos operacionais e des/incentivem o acesso a recursos de públicos ou privados, bem como formas de autogeração de receitas.

Mudanças em contextos regulatórios sobre as OSCs em diferentes países demonstravam path dependence e predominância de 
mudanças apenas incrementais (Bloodgood et al., 2014).

A Mesa de Articulação da América Latina e do Caribe, uma coalizão de OSCs do continente, num estudo de 2014, destacou que, na região, existe um ambiente regulatório favorável à ação dessas organizações, com claros casos tendendo para mais ou menos restrições a depender da área (Viveiros, 2014).

As tendências negativas observadas recaem sobre o excesso de controle burocrático-administrativo e outras restrições, incluindo a repressão a determinadas classes de OSCs. A visão do Estado presente em muitas dessas regulações e que deriva de pontos de vista específicos sobre modelos de desenvolvimento é a de que as OSCs se restringem a executores de políticas estatais à margem de deliberações efetivas, criando incentivos para que apenas um pequeno número de OSC ascendam a um espaço de "mercado" para acessar recursos públicos (Viveiros, 2014). No Brasil, em particular, a Constituição Federal (CF) 88 dá destaque ao possível papel complementar das OSCs em diversas políticas públicas, tais como saúde, educação, assistência, desporto, infância e juventude (Campos, 2008).

A Constituição Federal do Brasil reconhece, em seu art. 5o, a liberdade de reunião pacífica e a liberdade de associação para a realização de atividades lícitas, excluindo a ação armada, civil ou militar, como também assegura imunidades e isenções tributárias gerais, aplicadas a todas as OSCs (Storto, 2014).

Outro destaque da CF é a interação e par- ticipação das OSCs nos processos decisórios governamentais, com destaque para as legislações específicas sobre conselhos de políticas públicas nas três esferas governamentais (Lopes \& Abreu, 2014). Verifica-se a partir daí o incremento de espaços e articulações voltados à participação em temas ligados ao acesso à informação, à transparência e também a propostas para os modelos de desenvolvimento local (Storto, 2014).

Há uma série de regulações que se aplicam de forma seletiva a diferentes OSCs, de forma voluntária ou compulsória, como as que tratam de imunidades e isenções. $E$ há, por fim, as regulações, como as aprofundadas neste estudo, que se aplicam apenas a um conjunto ainda menor de OSCs que recebem financiamento estatal.

No âmbito federal, Lopes e Abreu (2014) destacam a percepção dos gestores públicos sobre as parcerias com OSCs, destacando como incentivos para sua realização: internalizar o conhecimento especializado dessas organizações, fortalecer a rede de atuação de ONGs e aproveitar sua capilaridade territorial e acesso a populações alvo específicas, além de ampliar a legitimidade da política pública e suprir a falta de quadros da burocracia para implementação e proximidade das demandas dos beneficiários diretos da ação.

Como desvantagens dessas parcerias, Lopes e Abreu (2014) apontam que há instabilidade nos quadros das OSCs, tendo em vista as dificuldades que encontram em angariar recursos para contratação e manutenção de funcionários. O Estado estaria em desvantagem também nos casos em que a totalidade ou grande parte de uma política fosse de- 
legada às OSCs, pois perderia expertise e correria o risco de descontinuidade.

Há também vantagens e desvantagens para as OSCs. Como principais vantagens estão a possibilidade de influenciar as políticas públicas a partir de inovações que produzem, contribuindo para a causa e a visibilidade de sua atuação como um todo, além da possibilidade de acessar recursos.

Na realidade, o acesso a recursos públicos tem se mostrado uma "faca de dois gumes" para essas organizações, podendo se converter em uma imensa desvantagem. Este é um dos pontos que tem sido mais estudado por pesquisadores em diversos países (Anheier, Toepler \& Sokolowski, 1997; Salinas, 2013; Gronbjerg, 1991, Lipskey \& Smith, 1990).

\section{Contexto recente e mobilizações por um Novo Marco Regulatório}

Até o início da década de 1990, a Legislação que norteava as relações Estado/OSCs datava dos anos de 1930 e necessitava ajustes (Comunidade Solidária, 1997). De acordo com Oliveira e Haddad (2001), a legislação ultrapassada reunia diferentes normas construídas a partir do Código Civil de 1916, não existia nenhuma tipologia de OSCs, apenas categorias frouxas, que, de acordo com os autores, privilegiavam certas categorias de organizações.

Foram iniciadas discussões por meio da Comunidade Solidária que buscavam reestruturar as bases institucionais que permeavam as relações governo/OSCs (Alves \& Koga, 2001). Nessas discussões, começou a ficar clara a necessidade de instrumentos legais distintos para a pluralidade de OSCs (Oliveira \& Haddad, 2001).

Durante esse período, novos marcos institucionais foram criados: o modelo de Organização Social (OS) - Lei 9.637/98 - e a Lei 9.790/99, que qualificou parte das pessoas jurídicas de direito privado sem fins lucrativos como uma Organização da Sociedade Civil de Interesse Público (OSCIP). Esta última, ainda, criou o Termo de Parceria, como proposta de melhoria em relação ao tradicional convênio (Ferrarezi, 2001, p. 16).

Apesar dessas inovações, não houve a substituição de uma legislação que já estava vigente, que era as dos convênios, apenas instituíram novos modelos que passaram a conviver com outros. Essa convivência de diferentes normas que vão se acomodando tem gerado insegurança jurídica, tanto para os gestores públicos, quanto para as OSCs (Junqueira \& Figueiredo, 2012). O que se observa é que a falta de clareza deu margem à que diferentes práticas de gestão por parte dos órgãos públicos contratantes fossem aceitas.

Houve inovações relevantes para as OSCIPs em relação à transparência, sendo obrigadas a submeter anualmente a auditorias internas e externas, e a tornarem públicas suas demonstrações financeiras e seus relatórios de atividades.

A adoção desse novo modelo institucional, conforme demonstraram Alves e Koga (2006), foi objeto de muitas resistências por parte das OSCs. Ainda há um desconhecimento dos modelos de Organização Social (OS) e OSCIP e de seus instrumentos jurídicos, formas de controle/acompanhamento 
e avaliação (Coutinho et. al. 2008), ou seja, a criação de outros instrumentos para parcerias acarretou em problemas tanto para os gestores públicos como para as OSCs (Carvalho, 2007).

A qualificação de OSCIP obteve baixa adesão por parte das OSCs, que permaneceram utilizando os convênios como instrumento jurídico para mediar as transferências de recursos pelo Estado, em vez da possibilidade de utilizar o Termo de Parceria. Entre os motivos que levaram à baixa adesão das OSCs ao modelo de OSCIPs estão um movimento de resistência ideológica por parte de muitas organizações, que identificam o modelo como um assalto neoliberal ao Estado e o risco de perda de autonomia das OSCs (Durão 2003; Oliveira \& Haddad, 2001).

Outros motivos podem ser ainda apontados, como ausência de maior detalhamento normativo, como existe nos convênios, mas, principalmente, a cultura e resistência dos gestores públicos, que ainda tem desconhecimento sobre o Termo de Parceria. Além disso, as procuradorias dos órgãos públicos que avaliam e acompanham a execução dos Termos de Parceria são os mesmos que analisam os convênios, tendendo-se a pautar-se pelos mesmos critérios, seguindo a instrução normativa aplicável aos convênios. (Barbosa, 2011, \& Trezza, 2007).

Alguns dos motivos que levaram a legislação das OSCIPs a "não pegar" parecem estar também por trás das dificuldades já visualizadas com o MROSC. Conforme já colocado por Alves e Koga (2006), o peso do passado tem exercido considerável influência na mudança regulatória das OSCs.
A inércia organizacional é um processo pelo qual as organizações mudam lentamente, quando confrontadas com mudanças não desejáveis (Stinchcombe, 1965). Uma vez que formatos e modelos já estão estabelecidos, eles tendem a seguir um curso de estabilidade, mesmo que as pressões ambientais indiquem que o modelo do passado não seja mais efetivo como costumava ser.

O que se aponta aqui neste estudo é que a inércia organizacional não está apenas atuando sobre as OSCs, que na primeira leva de mudanças na década de 1990 tiveram um papel forte de resistência à mudança, como apontado por Alves \& Koga (2006), mas principalmente sobre o Estado e as práticas dos gestores públicos.

A diferença entre os dois momentos é justamente o cenário político e a mudança de posição das OSCs, que passa de resistência a um processo de mudança regulatória a apoiadoras centrais no novo processo.

Com relação ao cenário político das OSCs, conforme apontado por Mendonça, Alves \& Nogueira (2013), destacam mudanças na arquitetura de financiamento dessas entidades, com a diminuição e redirecionamento programático do apoio da cooperação internacional para o desenvolvimento, na emergência de novos modelos e formatos de sustentabilidade financeira, em parte sustentada por doações de pessoas físicas e jurídicas; e pela crescente "mercantilização" nas relações com o Estado, pela perda de quadros para trabalharem nas áreas sociais, cujas políticas públicas incorporaram as próprias agendas das OSCs, e pela recente onda de criminalização das parcerias. Por parte do Estado, aumentam as pressões por mais 
transparência, eficiência e efetividade na execução de políticas públicas, consequências de uma maior vigilância da sociedade como um todo.

Entre 2007 e 2010, emergem denúncias envolvendo a transferência de recursos do governo federal para as OSCs. Neste contexto e pressionada pela cobertura de mídia, a Presidente Dilma Rousseff chega a suspender todos os repasses de convênios federais com OSCs em 2010. Em 2007, é instalada a CPI das ONGs que encerra seus trabalhos em 2010 com uma série de recomendações para aperfeiçoar os mecanismos "pelos quais se materializam a relação de parceria entre Poder Público e ONGs" (Brasil, 2011). Estava instalado um cenário generalizado de desconfiança que culmina com a criminalização das OSCs. Diante desse quadro, tanto o Governo Federal quanto as OSCs se mobilizam para aperfeiçoar os mecanismos que mediam suas relações.

Por parte do Governo Federal - o Sistema de Gerenciamento de Convênios (SICONV) - foi fortalecido e o Portal dos Convênios criado para dar maior transparência a esses instrumentos com a possibilidade de acesso público às informações. Novos procedimentos para a contratação de entidades foram criados, tornando obrigatória a realização de chamamento público (Figueiredo Lopes et al., 2013).

Diversas coalizões de OSCs, em particular entidades envolvidas com a agenda de defesa de direitos, como a ABONG, aproveitaram as eleições presidenciais de 2010 para lançar uma carta aos presidenciáveis, na qual requeriam uma política efetiva, instrumentos e mecanismos que garantissem se- gurança jurídica, regime tributário apropriado e autonomia das organizações (Ribeiro, 2013).

Um grupo de discussão sobre MROSC foi criado pelo Governo Federal em 2011, por iniciativa da Secretaria Geral da Presidência da República (SGPR), tendo feito diversas recomendações de mudança na legislação (Figueiredo Lopes et al., 2013). Parte das OSCs convidadas a participar desse grupo, especialmente as relacionadas às agendas de defesa de direitos, mas também com participação de outras redes como a do GIFE, lideram a criação da Plataforma do Marco Regulatório das OSCs, para continuar pressionando o Executivo e, em seguida, o Legislativo, para dar andamento às mudanças.

Essa mobilização foi longa e cheia de idas e vindas. O Executivo acaba não pautando o envio do projeto para o Congresso. Diante da falta de priorização da agenda pela presidência da República, buscou uma solução que pudesse acomodar os diversos interesses. Existiam alguns Projetos de Lei tramitando no Congresso sobre o marco regulatório das OSCs, motivo pelo qual se procurou viabilizar uma dessas propostas.

Em julho de 2014 foi aprovada a Lei 13.019, que regulamenta as parcerias entre Estado e Organizações da Sociedade Civil, com prazo inicial de 90 dias para entrar em vigor. Como resultado, nem todas as recomendações do GT da SGPR foram acatadas e a Lei retrocede com relação a diversas demandas das OSCs, representando uma norma que enfatiza a lógica burocrática-procedimental, com muitas exigências de difícil cumprimento, tanto pelo poder público, quanto pelas OSCs. 
No segundo semestre de 2014, a Secretaria Geral da Presidência da República (SGRP) realiza uma consulta pública para regulamentação colaborativa da Lei 13.019/14. Tal consulta ocorre em paralelo com a realização de diversas oficinas e encontros em várias partes do país. Houve uma grande mobilização tanto da Administração Pública, especialmente no âmbito municipal, como também de OSCs, alegando prazo insuficiente para adequação necessária, tanto de infraestrutura como de familiarização com as novas regras.

Nas novas mobilizações, outras OSCs aportam seu apoio na agenda MROSC, com destaque para as religiosas. Diversos pedidos de adiamento de entrada em vigor da Lei 13.019 por parte de OSCs e municípios são enviados ao governo federal, e os resultados da consulta colaborativa (SGPR, 2014) também apontavam sérios obstáculos para sua operacionalização.

O engajamento surte efeito e é publicada, em 30 de outubro de 2014, a Medida Provisória n. 658 , prorrogando o prazo de entrada em vigor, e novamente em 21 de julho de 2015, a Medida Provisória (MP) de 684, com novo adiamento. Com isso a Lei 13.019 retorna à casa Legislativa, onde passa a receber diversas emendas. Finalmente, em 14 de dezembro de 2015, é publicada a Lei 13.204, com significativas alterações de mérito na Lei 13.019/14.

\section{Principais mudanças no MROSC}

A Lei 13.019/14 instituiu um novo regime jurídico de parcerias Estado/OSCs, em âmbito nacional a partir de dois objetivos gerais: a) Colaboração: execução de políticas públicas contínuas em parceria Estado/OSCs; b) Fomento: ações de incentivo ou financiamento pelo estado de ações desenvolvidas pelas OSCs (Lopez et. al. 2014).

A grande mudança observada foi a extinção do uso de Convênios para celebração de parcerias entre Poder público e OSCs, reconhecendo que o instrumento do convênio não era compatível para esse tipo de parceria, pois ele foi concebido para parcerias entre entes federativos, ocasionando uma série problemas devido a falhas na legislação e falta de fiscalização da administração pública.

Foram criados novos instrumentos de mediação para substituir a utilização dos convênios: os termos fomento e colaboração. $A$ Lei 13.204/15 mantém esse direcionamento, incluindo também o Termo de Cooperação, que formaliza relações de parceria que não envolvam a transferência de recursos financeiros. O Quadro 1 esquematiza as principais mudanças com relação aos instrumentos jurídicos para transferência de recursos. 
Novo Marco Regulatório para a realização de parcerias entre Estado e Organização da Sociedade Civil (OSC). Inovação ou peso do passado?

\section{Quadro 1 - Termo de Colaboração e Termo de Fomento}

\begin{tabular}{|c|c|c|}
\hline & Termo de Colaboração & Termo de Fomento \\
\hline \multirow{3}{*}{ Diferenças } & $\begin{array}{l}\text { O plano de trabalho proposto pela } \\
\text { administração pública. }\end{array}$ & $\begin{array}{l}\text { O plano de trabalho proposto pela } \\
\text { organização da sociedade civil. }\end{array}$ \\
\hline & $\begin{array}{l}\text { A organização da sociedade civil estará } \\
\text { desenvolvendo atividades de interesse } \\
\text { público proposta pela administração } \\
\text { pública. }\end{array}$ & $\begin{array}{l}\text { A administração pública estará } \\
\text { fomentando atividades de interesse } \\
\text { público proposta pela organização da } \\
\text { sociedade civil. }\end{array}$ \\
\hline & $\begin{array}{l}\text { Os Conselhos de Políticas Públicas } \\
\text { podem apresentar propostas à } \\
\text { Administração Pública para celebração } \\
\text { de Termo de Colaboracão }\end{array}$ & \\
\hline \multirow{2}{*}{ Semelhanças } & \multicolumn{2}{|c|}{$\begin{array}{l}\text { Seleção através de Chamamento Público ("sempre que possível" procedimentos, } \\
\text { critérios e indicadores padronizados) } \\
\text { Plano de Trabalho com descrição do Projeto, objetivos, indicadores de resultado, } \\
\text { plano de aplicacão de recursos e prestação de contas } \\
\text { Exigência de } 3 \text { anos de existência da Organização no CNPJ }\end{array}$} \\
\hline & \multicolumn{2}{|c|}{$\begin{array}{l}\text { Comprovação de Capacidade técnica e experiência no objeto da parceria. } \\
\text { Discussão sobre como será feita a comprovação da capacidade técnica das } \\
\text { oCSs }\end{array}$} \\
\hline Observa & \multicolumn{2}{|c|}{$\begin{array}{l}\text { A padronização dos critérios do Chamamento Público e do Plano de Trabalho } \\
\text { para o Termo de Fomento pode apresentar problemas, pois esse instrumento foi } \\
\text { idealizado para promover iniciativas de OSCs. }\end{array}$} \\
\hline
\end{tabular}

Fonte: Elaboração própria a partir de informações da legislação: Brasil, Lei 13.019, de 31 de julho de 2014, e Lei 13.204, de 14 de dezembro de 2015

Uma das críticas feitas na Lei 13.019/14 foi a de que, apesar de criar dois instrumentos que priorizam demandas do setor público e as demandas das OSCs, a operacionalização de ambos era muito parecida, obedecendo às mesmas exigências, com excessiva ênfase na lógica burocrático-formal de controle (Panunzio, 2014). Ambos propunham a padronização de critérios e indicadores, entretanto isso, na Lei 13.2014, desaparece, tratando o texto não mais com indicadores quantitativos e qualitativos, mas com parâmetros de aferição de resultados.

A duas normas prezam pela transparência, tornando obrigatório o chamamento público, salvo casos justificáveis de dispensa ou inexigibilidade. Caem na nova norma exigências de tempo mínimo de existência e com- provação de capacidade técnica.

$\mathrm{Na}$ Lei 13.019, havia diversas exigências específicas no plano de trabalho, que foram simplificadas na Lei 13.204. Permanece, no entanto, um desafio para a gestão pública de articular a realização das parcerias com políticas, planos e programas governamentais, não apenas de realizar uma avaliação individual das parcerias. Para isso, é necessário que o poder público tenha clareza dos objetivos da parceria, o que nem sempre parece estar claro para os gestores públicos (Lopez \& Abreu, 2014), evidenciando a ausência de visão estratégica sobre as parcerias.

O quadro 2 destaca as principais novidades do novo MROSC e compara as Leis 13.019 e 13.204. 
Quadro 2 - Destaques da Lei 13.019/14 e da Lei 13.204/15

\begin{tabular}{|c|c|c|}
\hline & Lei 13.019/14 & Lei 13.204/15 \\
\hline Definição de OSCs & - & $\begin{array}{l}\text { Definição abrangente de } \\
\text { OSCs que inclui as entidades } \\
\text { religiosas e cooperativas } \\
\text { com atuação em áreas de } \\
\text { interesse público ou social. }\end{array}$ \\
\hline Exclusões & $\begin{array}{l}\text { OS - contratos de gestão } \\
\text { OSCIPS - termos de parceria }\end{array}$ & $\begin{array}{l}\text { Exclui também convênios e } \\
\text { contratos celebrados pelo } \\
\text { SUS; Termos de compromisso } \\
\text { cultural (Lei 13.018/14); } \\
\text { transferências do FNDE para } \\
\text { o PAED (escolas especiais) e } \\
\text { Programa Dinheiro Direto na } \\
\text { Escola - art. } 30\end{array}$ \\
\hline $\begin{array}{l}\text { Extinção do uso de } \\
\text { Convênios }\end{array}$ & $\begin{array}{l}\text { Reconhecimento de que o } \\
\text { instrumento do convênio não } \\
\text { é compatível para esse tipo de } \\
\text { parceria. }\end{array}$ & $\begin{array}{l}\text { Mantido, porem excluindo } \\
\text { os repasses do SUS, e } \\
\text { transferências específicas na } \\
\text { área de educacão }\end{array}$ \\
\hline $\begin{array}{l}\text { Abrangência Nacional } \\
\text { artigo 1ํㅡ }\end{array}$ & $\begin{array}{l}\text { Evita distorções de } \\
\text { implementação e gera } \\
\text { estabilidade nas parcerias. } \\
\text { Pode gerar dificuldades de } \\
\text { adaptação, principalmente } \\
\text { entre Estado e Municípios } \\
\text { com realidades e capacidades } \\
\text { diferentes. }\end{array}$ & $\begin{array}{l}\text { Criterios de exigência de } \\
\text { tempo de existência das } \\
\text { OSCs diferente para União, } \\
\text { Estados e Municípios para } \\
\text { celebração } \\
\text { Dificuldades } \\
\text { implementação de } \\
\text { permanecer }\end{array}$ \\
\hline $\begin{array}{l}\text { Obrigatoriedade } \\
\text { Chamamento Público }\end{array}$ & $\begin{array}{l}\text { Nos artigos } 23,24 \text { e } 27 \text { são } \\
\text { descritas as diretrizes para } \\
\text { realização do Chamamento } \\
\text { Público. } \\
\text { Possibilita a ampla publicidade } \\
\text { e evita irregularidades. }\end{array}$ & $\begin{array}{l}\text { Simplifica algumas exigências } \\
\text { - retira exigência de tempo de } \\
\text { existência mínimo da OSCs e } \\
\text { comprovação de experiência }\end{array}$ \\
\hline $\begin{array}{l}\text { Contrapartidas } \\
\text { Certificações }\end{array}$ & $\begin{array}{l}\text { Extinção da contrapartida } \\
\text { financeira e não exigência } \\
\text { de as OSCs apresentarem } \\
\text { certificações ou títulos para } \\
\text { celebração de parcerias. }\end{array}$ & $\begin{array}{l}\text { Idem } \\
\text { Na prática acaba com o } \\
\text { título de Utilidade Pública } \\
\text { ao ampliar para as OSCs, } \\
\text { definidas na Lei, os } \\
\text { benefícios antes atrelados } \\
\text { com esta titulacão - art. } 84\end{array}$ \\
\hline
\end{tabular}


Novo Marco Regulatório para a realização de parcerias entre Estado e Organização da Sociedade Civil (OSC). Inovação ou peso do passado?

\begin{tabular}{|c|c|c|}
\hline $\begin{array}{l}\text { Plano de trabalho detalhado } \\
\text { (Art. 22) }\end{array}$ & $\begin{array}{l}\text { Maior detalhamento do plano } \\
\text { de trabalho, com diagnósticos } \\
\text { prévios e definição de } \\
\text { indicadores de resultados. } \\
\text { Desafio em articular a } \\
\text { realização do diagnóstico da } \\
\text { realidade com políticas, planos } \\
\text { e programas governamentais. } \\
\text { Adaptação de ordem } \\
\text { administrativa e cultural ao } \\
\text { modelo de foco em resultados. }\end{array}$ & $\begin{array}{l}\text { Exigências simplificadas - } \\
\text { não exige mais indicadores } \\
\text { quantitativos e qualitativos, } \\
\text { mas sim parâmetros mínimos } \\
\text { de aferição, detalhamento de } \\
\text { diversos valores em rubricas } \\
\text { específicas }\end{array}$ \\
\hline $\begin{array}{l}\text { Prestação de contas } \text { e } \\
\text { capacidade institucional do } \\
\text { Estado e das OSCs (Art. } 63 \\
\text { e 71) }\end{array}$ & $\begin{array}{l}\text { Regras simplificadas para } \\
\text { prestação de contas abaixo de } \\
\mathrm{R} \$ 600.000,00 \text {. }\end{array}$ & $\begin{array}{l}\text { Prestação de contas } \\
\text { simplificadas para todas as } \\
\text { parcerias }\end{array}$ \\
\hline Contratação de pessoal & $\begin{array}{l}\text { Inclusão das despesas com } \\
\text { remuneração do pessoal não } \\
\text { superior à do teto do Executivo, } \\
\text { e apenas os com carteira } \\
\text { assinada. } \\
\text { Inclusão de encargos } \\
\text { trabalhista relacionados ao } \\
\text { projeto no orçamento. }\end{array}$ & Tdem \\
\hline Regulamento de compras & $\begin{array}{l}\text { Submissão do regulamento } \\
\text { de compras à administração } \\
\text { pública }\end{array}$ & $\begin{array}{l}\text { Elimina a necessidade } \\
\text { regulamento próprio de } \\
\text { compras }\end{array}$ \\
\hline $\begin{array}{lr}\text { Controles } & \text { e } \\
\text { responsabilização } & \text { dos } \\
\text { dirigentes } & \end{array}$ & $\begin{array}{l}\text { Os dirigentes são } \\
\text { solidariamente responsáveis } \\
\text { pelas parcerias firmadas com o } \\
\text { poder público. }\end{array}$ & $\begin{array}{l}\text { Cai a responsabilização } \\
\text { solidária dos dirigentes } \\
\text { atuando na gestão executiva } \\
\text { de acordo com limites de } \\
\text { mercado }\end{array}$ \\
\hline Remuneração de dirigentes & - & $\begin{array}{l}\text { Permitida a remuneração de } \\
\text { dirigentes }\end{array}$ \\
\hline Redes & $\begin{array}{l}\text { As OSCs têm a oportunidade } \\
\text { de atuar em rede para } \\
\text { execução de projetos de } \\
\text { interesse público, porém a } \\
\text { responsabilidade recai sobre } \\
\text { a organização que celebrar } \\
\text { formalmente a parceria com a } \\
\text { Administracão Pública. }\end{array}$ & $\begin{array}{l}\text { Tdem } \\
\text { Adiciona critério de existência } \\
\text { mínima de } 5 \text { anos para } \\
\text { celebrante com execução em } \\
\text { rede e exige comprovação de } \\
\text { capacidade de coordenação }\end{array}$ \\
\hline
\end{tabular}

Fonte: Elaboração própria a partir de informações da legislação: Brasil, Lei n. 13.019, de 31 de julho de 2014, e Lei 13.204 , de 14 de dezembro de 2015 


\section{O novo MROSC: inovação ou peso do passado?}

Percebe-se que houve uma evolução entre as Leis 13.019 e 13.204 com relação a orientações menos formais desta última, e uma maior valorização das OSCs e sua diversidade. Alguns mecanismos que poderiam estimular boas práticas de governança das OSCs, como a exigência de conselho fiscal e de regulamento próprio de compras, foram retirados e abrandados alguns mecanismos de controle na prestação de contas.

No entanto, os ganhos obtidos pelas OSCs na nova Lei, bem como oportunidades para aperfeiçoamento, podem ser novamente objeto de mudanças na sua regulamentação por meio dos decretos, o que mantém a necessidade de que a mobilização das entidades com o poder público continue.

Pensando o novo MROSC como processo de mobilização entre as OSCs e o poder público, não apenas como o reflexo de suas normas, é possível verificar um caráter inovador no próprio dialogo estabelecido entre gestores públicos, OSCs e órgãos de controle, que desnudam os desconhecimentos, preconceitos e dificuldades de entendimento presentes na atuação das entidades. Em termos de regulamentação, as inovações ficam por conta da possibilidade de atuação em rede das OSCs, da criação de um instrumento específico para propostas das OSCs e de outro que permita a cooperação para além da transferência de recursos e da preocupação com a transparência e com critérios mais claros para a realização dos chamamentos públicos, com ênfase no controle de resultados.
Há elementos que aprofundam ou complementam os pressupostos contidos no arcabouço da Reforma Administrativa, como gestão por resultados e enfoque na eficiência dos gastos públicos (Mare, 1995; Bresser Pereira, 1998). Esses são os pressupostos também encontrados na legislação sobre OS e OSCIPs. O Termo de Parceria contemplava a possibilidade de realização de chamamento público, com concursos de projetos, mas também deixava espaço para a discricionariedade do gestor público na escolha das entidades a apoiar, um ponto que mereceria aperfeiçoamento na Legislação. Nesse instrumento de mediação, também se previu a formalização de resultados a serem alcançados com a parceria.

No entanto, diversos estudos apontaram problemas na utilização dos Termos de Parceria, bem como na qualificação das OSCs como OSCIPs (Alves \& Koga, 2006; Trezza, 2007; Barbosa, 2011; Lemos, 2006; Coutinho, 2009), entre eles cultura da administração pública e o desconhecimento dos gestores públicos acerca do modelo OSCIP no seu formato jurídico, como também na sua proposição de controle de resultados. Com isso muito órgãos preferiram, ao longo dos anos, não celebrar Termos de Parceria (Trezza, 2007; Lemos, 2006).

Coutinho (2009) em seu estudo sobre as OSIPCs em MG destacou que os servidores, bem como suas assessorias jurídicas, se sentiam inseguros com relação a diversos pontos, como o fato de que uma OSCIP pode realizar compras sem licitação. Outra insegurança é de ordem cultural, relacionada ao fato de mudança de papéis estabelecidos ante a adoção do modelo de parcerias, que exige um olhar para além da lógica de fun- 
cionamento do poder público. Essa barreira cultural se depara com o fato de que o gestor público deve fortalecer sua capacidade de formulação e monitoramento para atuar com parceiros. Também exige a interação com as OSCs, que muitos gestores públicos desconhecem ou tem pouco contato.

As próprias OSCs também demonstraram desconhecimento e resistência à adoção do modelo de OSCIPs. A interação com o Estado é muitas vezes custosa e complicada para essas organizações. É necessário lidar com diversos requisitos administrativos e legais, tais como a prestação de contas dos recursos utilizados e dos resultados alcançados (Coutinho, 2009). Há também resistência de ordem ideológica por parte de algumas entidades, que veem no modelo uma forma de privatização ou de "patrulhamento" burocrático do Estado (Alves \& Koga, 2006).

Por fim, o modelo de OSCIPs teve pouca disseminação entre os órgãos de controle, muitos auditores não dominavam completamente as especificidades do modelo. Tanto os órgãos de controle quanto os gestores públicos apresentaram dificuldade de trabaIhar com o modelo de gestão por resultados (Coutinho, 2009).

Ao observar que muitos elementos da Legislação das OSCIPs continuam presentes no MROSC de 2014, tais como controle de resultados, por meio de um plano de trabalho mais detalhado, publicização e regras para realização de chamamento público e regulamento de compras. Observa-se que muitas das barreiras culturais enfrentadas pela legislação das OSCIPs continuarão presentes no modelo proposto pelo MROSC.
A cultura da gestão pública e seu aparato administrativo-jurídico continuam voltados para o controle formal de meios. Por esse motivo, ainda permanecem sendo amplamente utilizados os convênios como instrumento de mediação jurídica dessas parcerias, por ser um modelo conhecido e praticado pelos gestores públicos em todos os níveis de atuação governamental, mesmo quando as parcerias com as OSCs apresentam diversos problemas.

É observado no MROSC um movimento contraditório. Na primeira Lei, houve excessiva ênfase na lógica burocrático-formal de controle (Pannunzio, 2014). Já na segunda Lei, o reconhecimento da diversidade das OSCs e a flexibilização de vários critérios se fazem presentes, destacando a autonomia das entidades.

Os problemas verificados nas OSCIPs e que se repetem no MRSC são ausência de coordenação e divisão de papéis e limites para a atuação das diversas instâncias de controle envolvidas (auditoria externa, conselho fiscal, órgão público, comissão de monitoramento e avaliação, CGU, TCU etc.). A questão da coordenação institucional ainda permanece em aberto, fazendo com que os atores que aplicam e interpretam a legislação continuem tendo comportamentos contraditórios, com base na leitura subjetiva de cada controlador. Esse último ponto fica reforçado com as exclusões de várias modalidades de parcerias do novo MROSC, o que mantém a sobreposição de várias normas.

\section{Considerações finais}

Após a análise das parcerias entre Estado/ OSCs sob a perspectiva do MROSC, foram 
levantados alguns pontos em relação ao possível impacto e consequências da legislação quanto a solucionar problemas de insegurança jurídica e propiciar condições mais favoráveis para a mediação das relações (Mendonça, Alves \& Nogueira, 2013).

Não se negam os grandes avanços que o novo marco trouxe, como remuneração da equipe e de custos indiretos (despesas administrativas), obrigatoriedade do chamamento público, atuação em rede e extinção da contrapartida financeira. Legislações anteriores relacionadas às parcerias entre Estado e OSCs já traziam em suas premissas questões consideradas agora inovadoras, MORSC, como transparência e controle de resultados.

Os principais pontos negativos se referem às exclusões de várias modalidades de contratos de parceria, o que enfraquece o processo de coordenação institucional e não contribui para garantir a segurança jurídica das parcerias.

Diversas análises foram realizadas sobre as mudanças regulatórias na década de 1990, demonstrando que considerável inércia organizacional recaia sobre as OSCs (Alves \& Koga, 2006), mas também sobre o próprio Estado (Barbosa, 2011; Trezza, 2007; Lemos, 2006; Coutinho, 2009), destacando barreiras ideológicas, gerenciais (dificuldade em trabalhar com a perspectiva de controle de resultados e de atuar de forma mais intensa na formulação de políticas) e culturais (falta de conhecimento sobre o ambiente regulatório, bem como conflitos interpretativos das legislações e falta de conhecimento e prática de relacionamento com as OSCs).
Dessa forma, o peso do passado atua influenciando nas próprias mudanças regulatórias, mas também nos efeitos que elas terão nos processos de implementação das políticas públicas.

Momentos críticos vivenciados ao longo da década de 2000 entre as OSCs e o Estado vieram a reforçar a trajetória de controle estatal para lidar com as dificuldades causadas pela insegurança jurídica e os desvios encontrados nas relações Estado/OSCs. Em um primeiro momento de mobilização do novo MROSC, transparece a visão limitadora do Estado com relação às OSCs, personificando-se na Lei 13.019/14, de caráter bastante restritivo para as entidades.

O caráter restritivo se impôs também ao poder público, especialmente aos municípios que reforçam a mobilização das OSCs por simplificações, forçando não somente dois adiamentos para entrada em vigor da Lei, como também a produção de uma nova norma, a Lei 13.204/15.

Essa foi uma mobilização positiva, pois aproximou gestores públicos, órgãos de controle e universidades para as discussões sobre a regulação, que extrapolaram para a compreensão mais ampla da diversidade das OSCs e seu importante papel como parceiras do Estado.

O resultado foi uma "virada de mesa" no MROSC, pois a Lei $13.204 / 15$ trouxe uma visão positiva das OSCs, afastando-se do mero reforço do controle para a promoção das parcerias. No espírito do MROSC, permaneceram ainda os esforços na promoção da transparência e do fortalecimento das OSCs, com a criação do Termo de Fomento. 
O que se percebe é que a tensão sobre a visão do Estado frente às OSCs ainda está presente. Entre os pedidos de vetos aos artigos mais flexibilizantes da Lei 13.204/15, mais de 80 vieram da burocracia pública. $A$ cultura de desconfiança permanece. Consideramos que o processo ainda terá desdobramentos no momento de regulamentação da Lei e da sua aplicação pelos diversos atores envolvidos.

Conforme discutido, o rompimento do padrão de controle burocrático ainda é um desafio para a gestão pública como um todo, pois diversos elementos de inércia organizacional se combinam para que ele se mantenha. Está em jogo também uma cultura em que a confiança nas relações precisa continuar sendo construída e constantemente reforçada. Isso impõe desafios para que a mobilização que levou ao novo MROSC se amplie.

A cultura da gestão pública, bem como seu aparato administrativo-jurídico continua voltada para o controle formal de meios. $O$ que se defende, segundo a linha de Modesto (1998) "é uma análise da gestão de parceria, uma compreensão para além da aplicação da legislação". Ao se concentrar apenas nas questões legais, sem levar em conta outras dimensões das relações entre Estado/ OSCs, o poder público não articula uma visão estratégica acerca das parcerias, o que não ajuda a superar as barreiras institucionais, gerenciais e culturais aqui descritas.

\section{Referências}

Abong. (2014). Entenda o PL 7.168/2014 de $A$ a $Z$. Organização em defesa dos di- reitos e bens comuns. Recuperado em 20 maio, 2015, de www.abong.org.br/noticias. php?id=7429

Alves, M. A., \& Koga, N. M. (2006). Brazilian nonprofit organizations and the new legal framework: an institutional perspective. BAR. Brazilian Administration Review, v. 3, p. 5.

Anheier, H. K., Toepler, S., \& Sokolowski, W. (1997). The implications of government funding for non-profit organizations: Three propositions. International Journal of Public Sector Management, 10(3), 190-213.

Barbosa, M. N. L. (2011). A experiência dos termos de parcerias entre o poder publico e as organizações da sociedade civil de interesse público (OSCIPS). In: Sundfeld, C (Org.). Parcerias Público-Privadas. $2 a$ ed. São Paulo: Malheiros Editores Ltda, v. 1, pp. 522-562.

Bloodgood, E.; Tremblay Boire, J., \& Prakash, A. (2013). National styles of NGO regulation. Nonprofit and Voluntary Sector Quarterly 2014, v. 43(4) 716-736. The Author(s).

Bottesi, C. C. (2014). Lei Federal 13.019/14: Mais cuidados no repasse ao terceiro setor. Tribunal de Contas do Estado de São Paulo. Recuperado em 30 abr., 2015, de www4.tce. sp.gov.br/sites/default/files/20140818_artigo_terceirosetor1_0.pdf

Brasil Lei n. 9.637 de 15 de Maio de 1998. Dispõe sobre a qualificação de entidades como organizações sociais. Diário Oficial da União, Brasília, DF. 18 mai. 1998. Seção 1, página 8.

Brasil. Código Civil. Quadro Comparativo 
1916/2002. Senado Federal, Subsecretaria de Edições Técnica. Brasília, 2003. Recuperado em 20 jan., 2015, de www2.senado.leg. br/bdsf/item/id/70309

Brasil. Congresso Nacional (2010). Comissão Parlamentar de Inquérito "das ONGs". Relatório final da "CPI das ONGs". Brasília. Recuperado em 15 abr., 2015, de www2.senado.leg.br/bdsf/item/id/194594

Brasil. Lei n. 13.019, de 31 de julho de 2014. Dispõe sobre as parcerias voluntárias. Diário Oficial da União, Brasília, DF. 01 fev. 2014, Seção 1, página 1.

Brasil. Lei n. 9.790, de 23 de março de 1999. Dispõe sobre a qualificação de pessoas jurídicas de direito privado, sem fins lucrativos. Diário Oficial da União, Brasília, DF. 24 mar. 1999. Seção 1, página 1.

Bresser Pereira, L. C. (1998). Uma reforma gerencial da administração pública no Brasil. Revista do Serviço Público, Brasília, v. 49, n. 1, pp. 5-42, jan.-mar.

Brinkerhoff, J. M., \& Brinkerhoff, D. W. (2002). Government- Non-Profit relations in comparative perspective: evolution, themes and new directions. Public Administration and Development, 22, pp. 3-18.

Campos. L. C. (2008). ONGs/AINDS: Acesso a fundos públicos e sustentabilidade de ações. RAE - Revista de Administração de Empresas, v. 48, n. 3 jul.-set. Recuperado em 10 dez., 2014, de www.scielo.br/scielo.php?script=sci_arttext\&pid $=$ S0034-75902008000300008

Carvalho Neto, A. A. de. (2007). Transferên- cia de recursos do orçamento da união para organizações não governamentais: análise dos procedimentos de concessão e controle. 146 f. Monografia (especialização), Instituto Serzedello Corrêa do Tribunal de Contas da União e Centro de Formação, Treinamento e Aperfeiçoamento da Câmara dos Deputados, Brasília, DF.

Coutinho, F. de M. (2009). Os Desafios do Controle de Resultados nas Organizações da Sociedade Civil de Interesse Público (OSCIP): Um estudo do caso de Minas Gerais. In: // Congresso do Consad Gestão Pública, Brasília. Congresso Consad de Gestão Pública, 2, Brasília. Anais.

Coutinho, F. de M.; Bernardo, R. A., \& Silva, F. A. (2008). Contratualização de resultados com o terceiro setor (OSCIP), desafios e potencialidades: a experiência de Minas Gerais. In: Congresso Consad de Gestão Pública, 1, Brasília. Anais. Recuperado em 10 jan., 2015, de http://banco.consad.org.br/ handle/123456789/82?mode=full

Durão, J.E. S. (2014). O novo marco legal das OSC: avanço a se comemorar ou vitória de Pirro? Abong. Recuperado em 12 fev., 2015, de www.abong.org.br/noticias.php? $\mathrm{id}=7658$

Fagundes, L.; Silva, V., \& Silva, C. G. (2014). Certificações públicas concedidas às organizações da sociedade civil no Brasil. Entre dimensões normativas e complexidades contextuais. Cadernos Gestão Pública e Cidadania, São Paulo, v. 19, n. 64, jan.-jul. Recuperado em 12 fev., 2015, de http://bibliotecadigital.fgv.br/ojs/index.php/cgpc/article/ viewFile/8930/25690

Ferrarezi, E. (2002). Saiba o que são Orga- 
nizações da Sociedade Civil de Interesse Público - OSCIP. Brasília-DF: Agência de Educação para o Desenvolvimento - AED, v. $1.88 \mathrm{p}$.

FGV Projetos. (2014). Pesquisa sobre Organizações da Sociedade Civil e suas parcerias com o Governo Federal. FGV Projetos. Recuperado em 10 mar., 2015, de www. secretariageral.gov.br/atuacao/mrosc/estudos-e-pesquisas/sumario-executivo-fgv.pdf

Figueiredo Lopes, L., Araújo Jr., E., Souza, A., \& Sant'Ana, D. (2013). As parcerias entre o Estado e as Organizações da Sociedade Civil no Brasil: a formação de uma agenda de mudança institucional e regulatória. Novena Conferencia Regional de ISTR Santiago de Chile. Recuperado em: 20 jan., 2015, de www.secretariageral.gov.br/atuacao/ mrosc/estudos-e-pesquisas/sg-novena-conferencia

Gronbjerg, K. (1991). Managing grants and contracts: The case of four nonprofit social service organizations. Nonprofit and Voluntary Sector Quarterly, 20, 5-24.

Hall, P., \& Taylor, R. (2003). As três versões do neoinstitucionalismo. n. 58. Lua Nova, São Paulo.

www.enap.gov.br/index.php?option=com docman\&task=doc_view\&gid=2888. Acesso em: 10 de Agosto. 2014

http://www.scielo.br/pdf/cp/n112/16101.pdf. Acesso em: 10 de Novembro. 2014

IBGE. (2012). Fundações Privadas e Associações sem fins lucrativos (Fasfil). 3a ed. Rio de Janeiro, IBGE.
Instituto Pro Bono. (2005). Manual do terceiro setor. São Paulo: [s.n]. Recuperado em 30 abr., 2015, de www.probono.org.br/arquivos/ file/manualterceirosetor.pdf.

Junqueira, L. P., Figueiredo, M., et al. (2012) Modernização do sistema de convênio da Administração Pública com a sociedade civil. Série Pensando o Direito, v. 41. Brasília: Ministério da Justiça. Recuperado em 25 ago., 2014, de http://participacao.mj.gov. $\mathrm{br} /$ pensandoodireito/wp-content/uploads/2013/03/Volume41.pdf

Lemos, C. (2006). Organização da Sociedade Civil de Interesse Público - OSCIP. In: ViIhena, R. et. al. (Org.). O Choque de Gestão em Minas Gerais: políticas da gestão pública para o desenvolvimento. Belo Horizonte: Editora UFMG, pp. 129-144.

Lipskey, M., \& Smith, S. (1990). Nonprofit organizations, government and the welfare state. Political Science Quarterly, 104, 625-648.

Lopes, F. G., \&Abreu, R. (2014). A participação das ONGs nas políticas públicas: o ponto de vista de gestores federais. Brasília: Ipea. (Texto para Discussão, n. 1.949). Recuperado em 10 nov., 2014, de www.participa. br/articles/public/0008/5677/ponto_de_vista_dos_gestores_federais.pdf.

Lopez, Felix. Figueiredo Lopes, L., Souto, B., \& Sant'Ana, D. (2014). A interação entre organizações da sociedade civil e governo federal: Colaboração nas políticas públicas e aperfeiçoamentos regulatórios possíveis. Brasil em desenvolvimento- Estado planejamento e políticas públicas. v. 2. Brasília: Ipea, 2014. Recuperado em 20 març., de 
www.secretariageral.gov.br/atuacao/mrosc/ artigos/brasil-em-desenvolvimento-2014-ipea.pdf

MARE (Ministério da Administração e Reforma do Estado). (2001). Plano diretor da reforma do aparelho do Estado e organizações sociais. Revista Jus Navigandi. Teresina, ano 6, n. 51. Recuperado em 10 nov., 2014, de http://jus.com.br/artigos/2168

Mendonça, P., \& Segatto, C. I. (2014). Reflexões sobre a relação entre as Organizações da Sociedade Civil (OSCs) e o Estado: Marco legal, mecanismos de financiamento e implicações para a gestão. In: XXXVIII Encontro da Anpad - EnAnpad 2014, Rio de Janeiro. Anais do XXXVIII EnAnpad, 2014. Recuperado em 10 març., 2015, de www.anpad.org. br/admin/pdf/2014_EnANPAD_APB1018.pdf

Mendonça, P., Alves, M. A., \& Nogueira, F. (2013). Quadro Geral da Arquitetura de Apoio: tendências e reflexões. In Mendonça, P. E. M, Alves, M. A., \& Nogueira, F. do A. (orgs.). Arquitetura Institucional de Apoio às Organizações da Sociedade Civil no Brasil. São Paulo: FGV, p. 25-41. Recuperado em 22 març., 2016, de http://ceapg.fgv.br/sites/ ceapg.fgv.br/files/u26/livro_articulacaod3. pdf

Modesto, P. (1998). Reforma do marco legal do terceiro setor no Brasil. Revista de Direito Administrativo (RDA), Rio de Janeiro, Renovar, n. 214, pp. 55-68, out.-dez. Revista do Serviço Público, Brasília, ano 48, n. 2, maio-ago., pp. 27-57.

Oliveira, A., \& Haddad, S. (2001). As organizações da sociedade civil e as ONGs de Educação. Cadernos de Pesquisa, n. 112. pp. 61-83.

Ostrom. E. (1990). Governing the commons: The evolution of institutions for collective action. New York: Cambridge University Press.

Pannunzio, E. (2014). Nota técnica sobre projeto de Lei 7.168/2014 ("Novo Marco Regulatório das OSCs”). CPJA/FGV. São Paulo. Recuperado em 20 març., 2015, de http:// cpja.fgv.br/publicacao/nota-tecnica-sobre-projeto-de-lei-71682014-novo-marco-regulatorio-oscs

Peci, A. (2013). Regulação e Administração Pública. In: Sérgio, G. (Org.). Regulação no Brasil: uma visão multidisciplinar. Rio de Janeiro: FGV, p. 98.

Peci, A., Figale, J., \& Sobral, F. (2011). The Invasion of Manufactured Civil Society: Government-Nonprofit Partnerships in a Brazilian State. Public Administration and Development (Print), v. 31, pp. 377-389.

Plataforma da sociedade civil pelo novo marco regulatório (2014). Primeira contribuição da plataforma das OSCs para o processo de regulamentação da Lei n. 13.019/2014. Brasília. Recuperado em 20 abr., 2015, de https:// observatoriosc.files.wordpress.com/2014/09/ proposta_regulamentac3a7c3a3o_lei13019_ plataformamrosc_final.pdf

Ribeiro, V. M. (2013). A luta por um marco regulatório para as organizações da sociedade civil. In: Congresso Consad de Gestão Pública, 6, Brasília. Anais... Brasília, 2013. Recuperado de 13 maio, 2015, de www.participa.br/articles/public/0008/5675/pesquisa-abong.pdf 
Salgado, V. A. (2013). Uma análise crítica dos modelos de parceria entre o poder público e entidades do terceiro setor. In: Congresso Consad de Gestão Pública, 6, Brasília. Anais... Brasília. Recuperado em 5 abr., 2015, de http://repositorio.fjp.mg.gov. $\mathrm{br} /$ consad/bitstream/123456789/1027/1/ C6_TP_UMA\%20AN\%C3\%81LISE\%20 CR\%C3\%8DTICA\%20DOS\%20MODELOS.pdf

Salinas, N. S. (2013). Modelos de controle das parcerias entre Estado e entidades do terceiro setor e desenho institucional das políticas públicas. Revista de Direito do Terceiro Setor, v. 7, pp. 9-28.

SGPR (Secretaria-Geral da Presidência da República). (2014). Relatório - Consulta Pública: Regulamentação Colaborativa, Lei 13.019/2014. Secretaria-Geral da Presidência da República, Brasília.

Stinchcombe, A. (1965). Social structure and organizations. In J. March (Ed). Handbook of organizations (pp. 142-193). Chicago: Rand-McNally.
Storto, P., Golfieri, M. et al. (2012) Modernização do sistema de convênio da Administração Pública com a sociedade civil. Série Pensando o Direito, v. 41. Brasília: Ministério da Justiça. Recuperado em 7 abr., 2015, de www.secretariageral.gov.br/atuacao/mrosc/ estudos-e-pesquisas/2013-sal

Trezza, V. (2007). O Termo de Parceria como instrumento de relação público/privado sem fins lucrativos: O Difícil Equilíbrio entre Flexibilidade e Controle. Dissertação de Mestrado em Administração Pública. EAESP, FGV.

Viveros, F. (2014) "Sintesís Comparativa: Marcos Jurídicos de lãs Organizaciones de La Sociedad Civil em los Paises Del Cono Sur e Brasil', Asociación Chilena de Organismos No Gubernamentales - ACCIÓN, documento preparado para El Proyecto Regional Mesa de Articulación de América Latina y el Caribe y sus Aliados Del Sur, Santiago. Recuperado em 22 març., 2016, de http://mesadearticulacion.org/wpcontent/uploads/2014/08/ Estudio-Subregional-marco-legal-OSCs-Cono-Sur.pdf 